\title{
Degradation of riboflavin by alimentary bacteria of the ruminant and man: production of 7,8-dimethyl-10-carboxymethylisoalloxazine
}

\author{
By D. W. WEST ANd E. C. OWEN \\ Biochemistry Department, \\ Hannah Research Institute, Ayr KA6 ${ }_{5} H L$ \\ (Received II November 1971 - Accepted I3 fuly 1972)

\begin{abstract}
1. A new product of the bacterial degradation of riboflavin has been isolated from fermentations in vitro of mixtures of either rumen bacteria or caecal bacteria with excess of the vitamin.

2. This product has been identified as 7,8-dimethyl-10-carboxymethylisoalloxazine and has also been shown to occur in the urine of ruminants and man.

3. The bacterial formation of this compound is compared with the bacterial formation of other isoalloxazines previously identified in similar incubation mixtures, and is discussed in relation to the factors influencing the mode of degradation of ribotlavin.
\end{abstract}

Riboflavin is known to be decomposed by specific bacteria. The first significant observation on this process was reported by Foster (1944), and studied subsequently by Yanagita \& Foster (I956), who demonstrated that Pseudomonas riboflavina catalysed the hydrolysis of riboflavin and ribitol, and obtained energy for growth by oxidation of the latter to carbon dioxide. This is an aerobic organism, and Miles \& Stadtman (1955) showed that the decomposition of riboflavin by an anaerobic soil micro-organism followed a different pattern with 7,8 -dimethyl-Io-( 2 '-hydroxyethyl)isoalloxazine (hydroxyethylflavin) occurring as the major product. The same isoalloxazine occurs in the urine of ruminants given large doses of riboflavin (Owen, 1962), and more recently (Owen \& West, 1970) it has been shown to be produced by the degradative action of the symbiotic bacteria in the gut of the animal.

7,8-Dimethyl-10-formylmethylisoalloxazine (formylmethylflavin), related to the above isoalloxazine, was also isolated from the urine of ruminants and from human urine when large doses of riboflavin were ingested (West \& Owen, 1969) and this compound was again shown to arise from bacterial degradation of the vitamin (Owen \& West, 1970). Both these products are formed by cleavage of the ribityl side-chain of the vitamin to give a three-carbon fragment, which is metabolized by the organism, and an isoalloxazine with a two-carbon side-chain which is not further metabolized. This pattern of degradation of riboflavin is similar to the photochemical degradation of riboflavin in that the same products arise in both processes (Hemmerich, Veegar \& Wood, 1965). One isoalloxazine that occurs in the photochemical degradative process but is as yet unreported as a biological product is 7,8-dimethyl-10-carboxymethylisoalloxazine (carboxymethylflavin), the acid corresponding to the aldehyde and alcohol mentioned above. The present communication reports the formation of this compound during the fermentation in vitro of either rumen or caecal contents and its occurrence in the urine of both ruminant and man. 


\section{EXPERIMENTAL}

Materials. Riboflavin was purchased from Koch-Light Laboratories, Colnbrook, Buckinghamshire. Mallinckrodt Silica A.R. CC-7, 200-325 mesh was used for silica gel column chromatography and Camag Kieselgel D5 (Griffin \& George, East Kilbride, Scotland) was used for silica gel thin-layer chromatography. All constituents of the bacteriological medium were purchased from Oxoid Ltd, London. Formylmethylflavin was prepared by the method of Fall \& Petering (1956), and carboxymethylflavin by permanganate oxidation of this aldehyde in aqueous solution by a method similar to that of Föry, MacKenzie \& McCormick ( 1968 ). The methyl ester of carboxymethylflavin was prepared by the method of Owen \& West (rg68).

Chromatography. Thin-layer and preparative-layer chromatography were carried out as previously described (West \& Owen, 1969). Four solvent systems were used: (a) chloroform-methanol ( $7: 3$, by volume); (b) chloroform-butanol-glacial acetic acid (5:4:I, by volume); (c) butanol-glacial acetic acid-water $(4: 1: 5$, by volume, upper phase); (d) chloroform-methanol-pyridine-glacial acetic acid (8:I:I:I, by volume). System (a) gave the most rapid development and was used in the isolation process. The other systems were used for the comparison of the $R_{F}$ values of the isolated compound with authentic materials.

Thin-layer electrophoresis. Silica gel thin-layer plates, as prepared for chromatography, were used for electrophoresis. They were sprayed with 0.01 M-potassium phosphate buffer, $\mathrm{pH} 7^{\circ} \mathrm{O}$, and briefly allowed to dry in air before the samples were applied. The electrophoretograms were examined in u.v. light to locate the fluorescent samples.

Recording of spectra. Proton magnetic resonance spectra were recorded with a ro $\mathrm{MHz}$ spectrophotometer (Varian Instruments Ltd, Palo Alto, California) using tetramethylsilane as internal standard. The mass spectrum was recorded on the negative ion spectrometer at the Manfred von Ardenne Institute, Dresden. The spectrum was recorded at $90^{\circ}$ at $5000 \mathrm{eV}$.

Bacteriological medium. The composition was: proteose peptone, $15 \mathrm{~g}$; liver digest, $2.5 \mathrm{~g}$; yeast extract, $5.0 \mathrm{~g}$; sodium chloride, Io $\mathrm{g}$; riboflavin, $0.5 \mathrm{~g}$; water to I I $(\mathrm{pH} 7 \cdot 4)$. All manipulations were carried out in a darkened laboratory to prevent photolytic decomposition of the isoalloxazines.

Extraction of metabolite from incubations of rumen bacteria. Rumen samples were obtained from a stall-fed Ayrshire cow or a similarly fed male castrated British Saanen goat by means of rumen fistulas approximately $4 \mathrm{~h}$ after food had been ingested. The samples were diluted I:I with artificial saliva (McDougall, I948) before being incubated with excess riboflavin ( $\mathrm{g} / \mathrm{l})$ at $37^{\circ}$ in amber, screw-topped bottles. After incubation for $7^{-10} \mathrm{~d}$, the culture was extracted with approximately three times its volume of a mixture of chloroform and methanol (I:I, by volume). The extract was removed and the aqueous layer again treated with the same volume of the chloroformmethanol mixture. This gave a clear, yellow, homogeneous solution from which a solid precipitated. The precipitate was filtered off and discarded, leaving a homogeneous, yellow filtrate; this was recombined with the previous organic extract and 
the whole was concentrated on a rotary evaporator under reduced pressure. Much unwanted yellow-fluorescing material in the resultant aqueous solution, including all the formylmethylflavin and hydroxyethylflavin formed during the incubation period, was removed by repeated extractions, each with the same volume of chloroform.

The extracted aqueous concentrate was then absorbed on to neutral silica gel and the moist silica was slurried in chloroform. This silica gel was dried by allowing the chloroform to evaporate, after which it was added to the top of a column containing the same adsorbent which had been freshly poured as a slurry in chloroform. The column was then washed through with chloroform containing $5 \%$ methanol, which seemed to be essential to remove the last traces of water from the sample. Elution was continued with chloroform-methanol ( $9: \mathrm{I}$, by volume) and then chloroform-methanol ( $4: r$, by volume) until no more fluorescent products were eluted. The required material was finally eluted from the column by the use of a chloroform-methanol ( $\mathbf{1}: \mathbf{1}$, by volume) mixture. This final eluate was concentrated in a rotary evaporator and transferred to a small volume of water. Addition to this aqueous solution of an equal volume of pyridine gave a yellow precipitate which was separated in a centrifuge. The supernatant fraction was discarded and the precipitate redissolved in methanol and painted on to preparative-layer chromatoplates. After development in solvent system (a), the band of silica containing the required material was scraped from the plates and eluted with methanol. This methanol solution was concentrated by evaporation, water was added and the final traces of methanol were removed under reduced pressure. The resultant aqueous solution was extracted three times with an equal volume of diethyl ether, then similarly with chloroform and finally with ethyl acetate. When this aqueous solution was poured into twice its own volume of acetone a yellow microcrystalline precipitate formed. This was filtered off and recrystallized from water to give the required product as bright-orange, needle-like crystals.

Extraction of metabolite from incubation of caecal bacteria. Samples of caecal bacteria were obtained either from a male castrated British Saanen goat by means of a caecal fistula or from freshly slaughtered kids. The bacteria were incubated at $37^{\circ}$ in stoppered, brown bottles in the bacteriological medium described. After $7 \mathrm{~d}$ the cultures were removed and treated in exactly the same way as the rumen incubations. The product was again isolated as bright-orange crystals.

Extraction of metabolite from urine samples. Urine was collected in amber bottles from a volunteer for a total of $48 \mathrm{~h}$ after ingestion of I $\mathrm{g}$ 7,8-dimethyl-IO-(D-ribityl5 -phosphate) isoalloxazine (flavinomononucleotide, FMN) in water. The fluorescent urines were combined and the isoalloxazines present were concentrated by phenol extraction (Crossland, Owen \& Proudfoot, I958). The phenol concentrate was extracted several times with twice its volume of a chloroform-methanol mixture $(3: \mathrm{r}$, by volume) and the extracts were combined and concentrated on a rotatory evaporator. This concentrated extract was then painted on to preparative-layer silica gel chromatoplates which were developed in solvent system $(a)$. The appropriate isoalloxazine band was scraped off, eluted with methanol and concentrated as before. A concentrated methanolic solution of the metabolite was obtained, by a similar procedure, from the urine of a goat which had ingested I $g$ FMN. 
Preparation of the methyl ester of the metabolite. The methyl ester of the isolated product was prepared by treating a methanolic solution of the material with hydrogen chloride and was obtaincd as a yellow crystalline solid which could be recrystallized from water. The metabolite recovered from the urine samples in methanolic solution was converted into the methyl ester in a similar manner, but crystalline products could not be isolated.

Proof of bacterial origin of the metabolite. When the identity of the metabolite had been established, the following series of experiments were carried out to ensure that the product arose from bacterial action and not simply by non-enzymic oxidation of formylmethylflavin during either the incubation period or the lengthy extraction process.

A rumen sample was obtained from a stall-fed Ayrshire cow in a similar manner to that previously described and diluted I:I with artificial saliva (McDougall, I948). One-half of this sample was incubated with riboflavin, and the other half without the addition of any isoalloxazines, both incubations being carried out at $37^{\circ}$ under conditions similar to those previously described.

After incubation for $7 \mathrm{~d}$, a portion of the sample incubated with riboflavin was painted on to preparative-layer chromatoplates which were then developed in solvent system (a). After development, the band of silica containing the metabolite was scraped from the plates and the fluorescent material eluted with methanol. This methanolic solution was assayed by thin-layer chromatography in the four solvent systems detailed earlier. In each solvent system the methanolic solution was shown to contain a yellow fluorescent material that had the same $R_{F}$ as an authentic sample of carboxymethylflavin, indicating that the metabolite was present in the incubation mixture before the extraction process.

After incubation for $7 \mathrm{~d}$, the rumen sample incubated without added riboflavin was treated in the following manner. A sample of the contents was removed without opening the bottle by a hypodermic needle inserted through the cap and immediately filtered into a sealed bijou bottle without exposure to the air. A syringe-type membrane filter holder fitted with a $0^{\prime}$ I $\mu$ pore filter (type GA9, Gelman Instrument Co, Ann Arbor, Michigan, USA) was used for this purpose. The bijou bottle, which was foilwrapped to exclude light, contained riboflavin (about $4 \mathrm{mg}$ ) and was filled with a mixture of nitrogen and hydrogen ( $19: x$, by volume) after having been twice evacuated and flushed with this gas mixture. After Io min had been allowed for sufficient of the isoalloxazine to dissolve, a sample of the contents was removed without opening the bottle and filtered through a sterile GAg filter into a sterile, foil-wrapped bijou bottle filled with the same nitrogen and hydrogen gas mixture.

This process was repeated with a second sample of the rumen contents using formylemethylflavin instead of riboflavin in the bijou bottle.

Both bijou bottles were then incubated at $37^{\circ}$ for $24 \mathrm{~h}$ before being assayed for the presence of carboxymethylflavin by thin-layer chromatographic procedures. No evidence of the formation of carboxymethylflavin from either riboflavin or carboxymethylflavin could be obtained under these conditions. 
Table I. Relative abundance of the major peaks in the negative ion mass spectrum of the riboflavin bacterial metabolite 7,8 -dimethyl-10-carboxymethylisoalloxazine (carboxymethylflavin)

\begin{tabular}{lr}
$\mathrm{m}: \mathrm{e}^{*}$ & Relative abundance \\
284 & $4 \mathrm{I}$ \\
$27 \mathrm{r}$ & 69 \\
270 & 95 \\
258 & 37 \\
257 & 84 \\
256 & 100 \\
243 & 71 \\
$\mathbf{2 4 2}$ & 98 \\
I99 & $\mathrm{I} 9$ \\
I98 & 20 \\
Temperature 90 & $\mathrm{C}$. Field $5000 \mathrm{eV}$. \\
\multicolumn{2}{c}{ * Ratio, mass to charge. }
\end{tabular}

RESULTS

The crystalline product obtained from the bacterial incubations was shown to be an isoalloxazine by its u.v. spectrum (Cresswell \& Wood, 1960) in acid and alkaline solution, and by its yellow fluorescence under u.v. light. Its behaviour on thin-layer chromatograms in a chloroform-methanol ( $9: \mathrm{I}$, by volume) solvent system indicated that it was a very hydrophilic compound and electrophoresis on thin-layer chromatoplates in phosphate buffer at $\mathrm{pH} 7.0$ suggested the presence of an acidic function, which was further indicated by its ability to form a methyl ester. The metabolite was insufficiently soluble in ${ }^{2} \mathrm{H}_{2} \mathrm{O}$ to provide a proton magnetic resonance spectrum adequate for a structural identification, but the spectrum did indicate that the two aromatic methyl groups of riboflavin were retained. The negative ion mass spectrum of the material (Table I) showed a degradative pattern similar to that obtained from other isoalloxazines (Tümmler, Steinfelder, Owen \& West, I97I). In particular, the two most abundant peaks at $\mathrm{m}$ : e 242 and 256 could be correlated with the structure of lumichrome and lumiflavin (Figs $\mathrm{r} e$ and $\mathrm{r} b$ respectively) as has been shown previously (Ardenne, Steinfelder \& Tümmler, I965; Tümmler et al. 1971). This was further evidence that the methyls at $\mathrm{C}_{7}$ and $\mathrm{C}_{8}$ of the isoalloxazine were in fact present in the metabolite and eliminated the possibility that the acid function of the unknown had arisen through oxidation of one of these groups (Hemmerich et al. I965). This suggested that the acid function was in fact a carboxyl group attached to part of the carbon side-chain at $\mathrm{N}_{10}$. Further evidence for this suggestion came from the mass spectrum since the peaks at m:e 270 and 284 could be fitted to the structures shown in Figs I $d$ and $x c$ respectively. The presence of only two carbon atoms in the side-chain was demonstrated by the proton magnetic resonance spectrum of the methyl ester of the unknown in deuterodimethyl sulphoxide (Table 2) and this spectrum confirmed that the unknown was in fact carboxymethylflavin (Fig. I $a$ ). Authentic samples of the carboxymethylflavin were prepared by the following methods. The methyl ester of the acid was prepared by photolytic decomposition of formylmethylflavin in methanol (Owen \& West, I968) and the ester de-esterified to the required acid by 


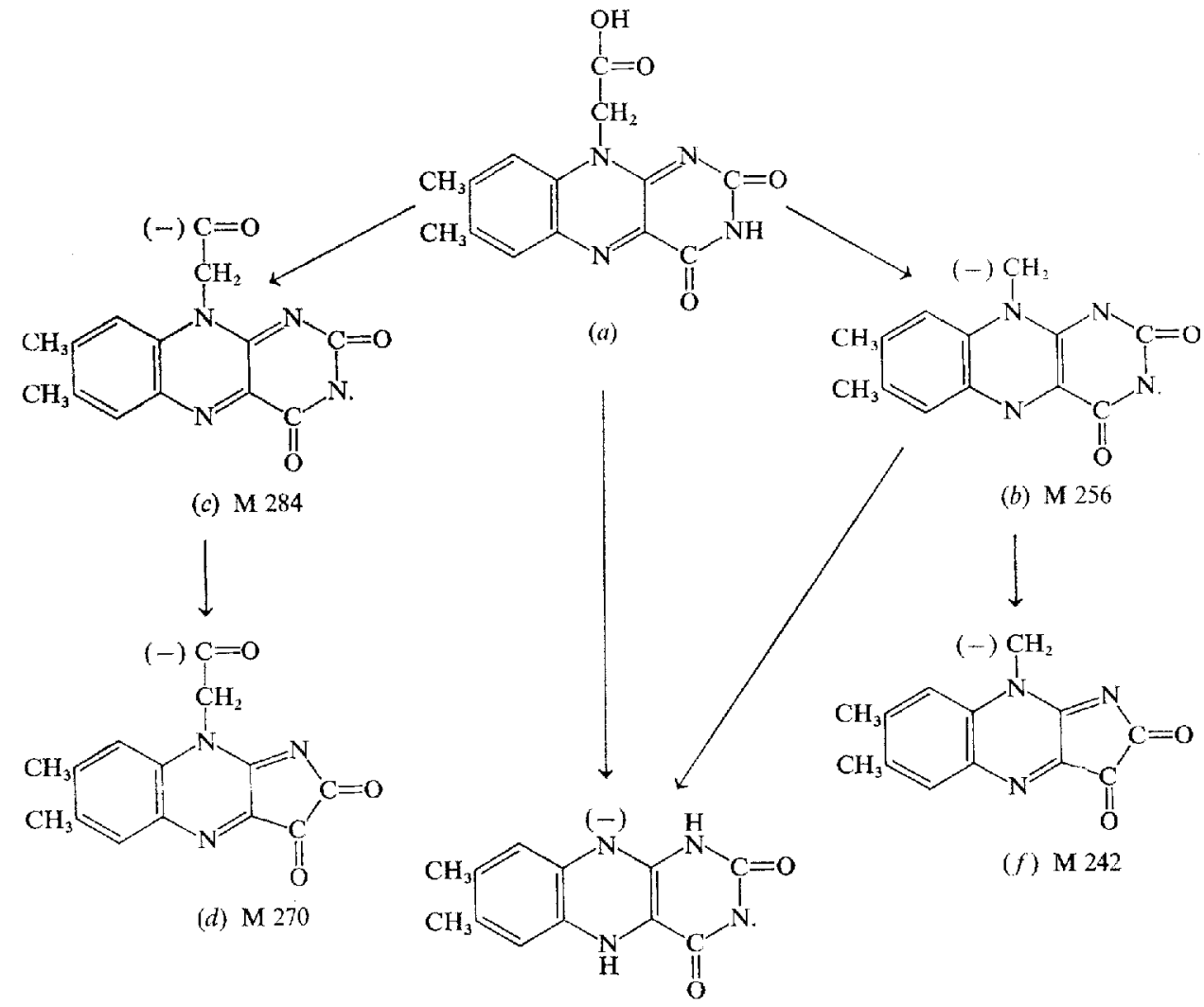

(e) $\mathrm{M} 242$

Fig. I. Suggested breakdown pattern of riboflavin bacterial metabolite in the negative ion mass spectrometer.

Table 2. Proton magnetic resonance values for the methyl ester of the bacterial degradation product in deuterodimethyl sulphoxide with tetramethylsilane as internal standard. Only one aromatic methyl is seen in this spectrum, the other is hidden by the dimethylsulphoxide resonance

\begin{tabular}{lcll}
$\tau$-Value & $\begin{array}{r}\text { Relative } \\
\text { intensity }\end{array}$ & $\begin{array}{c}\text { Appearance } \\
\text { Singlet }\end{array}$ & \multicolumn{1}{c}{$\begin{array}{c}\text { Assignment } \\
\text { Aromatic methyl }\end{array}$} \\
$7 \cdot 62$ & 3 & Singlet & $-\mathrm{COOCH}_{3}$ \\
$6 \cdot 3 \mathrm{I}$ & 3 & Singlet & $\mathrm{N}-\mathrm{CH}_{2}-\mathrm{CO}-$ \\
$4 \cdot 65$ & 2 & Singlet, singlet & Two $p$-aromatic protons \\
$2 \cdot 39,2 \cdot 24$ & $\mathrm{1}, \mathrm{r}$ &
\end{tabular}

treatment in the dark with $\mathrm{I} \mathrm{M}-\mathrm{NaOH}$ (Fukamachi \& Sakurai, 1955). Formylmethylflavin was suspended in water and oxidized to the corresponding acid with neutral potassium permanganate (Wu, MacKenzie \& McCormick, 1970). In each instance the product and the metabolite showed identical chromatographic behaviour on thinlayer chromatography in several solvent systems (Table 3 ) and on thin-layer electrophoresis in phosphate buffer. In addition, the methyl ester of the acid had the same 
Table $3 . \mathrm{R}_{\mathrm{F}}$ values of isoalloxazine derivatives in four solvent systems*

$$
(a),(b),(c) \text { and }(d)
$$

Isoalloxazine derivative

Hydroxyethylflavin $\dagger$

Formylmethylflavin

Carboxymethylflavin $\S$

Bacterial metabolite

Carboxymethylfavin

(methyl ester)

Bacterial metabolite

(methyl ester)

Riboflavin

\begin{tabular}{cccc}
\multicolumn{4}{c}{$R_{F}$ value } \\
\hline (a) & (b) & (c) & (d) \\
0.62 & 0.42 & 0.77 & 0.63 \\
0.71 & 0.67 & 1.0 & 0.79 \\
0.09 & 0.08 & 0.55 & 0.17 \\
0.10 & 0.08 & 0.54 & 0.17 \\
0.79 & 0.67 & 0.89 & 0.87 \\
0.79 & 0.66 & 0.89 & 0.89 \\
0.46 & 0.12 & 0.66 & 0.21
\end{tabular}

* (a), chloroform-methanol (7:3, by volume); (b), chloroform-n-butanolglacial acetic acid $(5: 4: 1$, by volume); (c), $n$-butanol-glacial acetic acid-water (4: $x: 5$, by volume, upper phase); (d), chloroform-methanol-pyridine-glacial acetic acid $(8: I: I: I$, by volume).

+ Hydroxyethylflavin $=7,8$-dimethyl-10-( $z^{\prime}$-hydroxyethyl)isoalloxazine.

+ Formylmethylflavin $=7,8$-dimethyl-ro-formylmethylisoalloxazine.

$\S$ Carboxymethylflavin $=7,8$-dimethyl-10-carboxymethylisoalloxazine.

$R_{F}$ values in these solvent systems as the methyl ester of the bacterial metabolite prepared as stated on p. $3^{6}$.

It was not possible to isolate pure crystalline samples of the metabolite from the samples of either human or goat urine, but the identity of the material obtained from each source was confirmed by thin-layer chromatographic techniques. The two samples and their methyl esters had $R_{F}$ values in four solvent systems that were identical with the $R_{F}$ values of authentic material under the same conditions.

\section{DISCUSSION}

With the identification of this metabolite as carboxymethylflavin we have now demonstrated that the bacteria inhabiting the rumen and the caecum can cleave the ribose portion of riboflavin to give a series of isoalloxazine derivatives related to the series ethanol:acetaldehyde:acetic acid (Owen \& West, 1970). Hydroxyethylflavin and formylethylflavin were the two major metabolites formed from riboflavin on incubation of rumen samples obtained just before the animals were fed (West, Owen \& Taylor, 1967 ). Small variable amounts of carboxymethylflavin were formed under these conditions. Adequate amounts of the latter metabolite were, however, formed on incubation of samples obtained from the rumen $4 \mathrm{~h}$ after food had been ingested. It is known that the bacterial population of the rumen varies considerably over this period, and this would suggest that different organisms were responsible for the formation of the different metabolites. However, the conditions pertaining in the rumen $4 \mathrm{~h}$ after feeding are more acid than the slightly alkaline conditions existing just before food is ingested. It is thus possible that the same organism is capable of yielding all three metabolites and that the $\mathrm{pH}$ of the rumen alters its metabolism sufficiently to account for the differences observed. This effect of $\mathrm{pH}$ on the fermentation of carbohydrates is a well-known phenomenon (Wood, I96I); a typical example is the 
alcoholic fermentation of yeast, which can be altered to provide a significant amount of acetic acid by incubation under alkaline rather than acid conditions. The fact that caecal bacteria incubated with riboflavin in a buffered medium always gave rise to large amounts of all three metabolites can be used to support either hypothesis and this point will only be clarified by isolation of the organisms concerned.

When the whole animal is considered, other factors must be taken into account and can obviously affect the distribution of the various metabolites in the milk, and in the urine and other excreta. Thus, although formylmethylflavin was usually formed in large amounts, by comparison with hydroxyethylflavin, in the incubations of rumen contents, it was only a very minor component of the mixture of metabolites that appeared in the urine (Owen \& West, 1970). We (West and Owen, unpublished) have evidence that the differences in apparent output of this metabolite result from the activity of an aldehyde reductase in ruminant liver that reduces some of the absorbed formylmethylflavin to hydroxyethylflavin so that the latter becomes the main urinary product. A similar explanation can possibly be advanced to account for the origin of a proportion of the carboxymethylflavin in urine, since enzymes may exist in the body that are capable of oxidizing the aldehyde formylmethylflavin to the corresponding acid. One enzyme present in liver that might be capable of carrying out this conversion is xanthine oxidase ( $E C \times .2 .3 .2$; xanthine: oxygen oxidoreductase) since it is capable of oxidizing a wide variety of aldehydes. In fact, formylmethylflavin acts as an inhibitor of this enzyme rather than a substrate (West and Owen, unpublished). Other experiments to test this general thesis have been unsuccessful as yet and it seems probable that the bulk of the carboxymethylflavin appearing in ruminant urine arises from bacterial action in the gut.

The fact that carboxymethylflavin has been identified in human urine after the intake of a large excess of riboflavin correlates well with the reported occurrence of hydroxyethylflavin and formylmethylflavin in human urine under similar circumstances (West \& Owen. 1969). The identification of this third metabolite under these conditions, together with the fact that ruminant caecal bacteria invariably gave rise to large amounts of this material when suitably incubated, lends further support to our suggestion (West \& Owen, 1969) that the metabolites of riboflavin that appear in human urine are mainly attributable to the degradative effect of colonic bacteria acting upon the riboflavin that passes unabsorbed through the upper intestine. Whether these metabolites of riboflavin have any function is at present unknown. Hydroxyethylflavin and formylmethylflavin have detrimental properties, since both inhibit the phosphorylation of riboflavin by liver flavokinase in the rat (McCormick, Arsensis \& Hemmerich, 1963 ), but whether the liver flavokinase of man is equally affected has not been investigated. This obviously has implications as regards overdoses of the vitamin and would warrant further research.

We thank Dr K. H. Overton of the University of Glasgow for the determination of the proton magnetic resonance spectra and Drs K. Steinfelder and R. Tümmler of the Forschungsinstitut Manfred Von Ardenne, Dresden, for the negative ion mass spectrum. 


\section{REFERENCES}

Ardenne, M. von, Steinfelder, K. \& Tiimmler, R. (1965). Z. Chemie, Lpz. 5, 287.

Cresswell, R. M. \& Wood, H. C. S. (1960). F. chem. Soc. p. 4768.

Crossland, A., Owen, E. C. \& Proudfoot, R. (1958). Br. F. Nutr. 12, 312.

Fall, H. H. \& Petering, H. G. (1956). F. Am. chem. Soc. 78, 377.

Föry, W., MacKenzie, R. E. \& McCormick, D. B. (1968). J. heterocyclic Chem. 5, 625.

Foster, J, W. (1944). F. Bact. 47, 27.

Fukamachi, C. \& Sakurai, Y. (1955). \%. Vitam. 1, 217.

Hemmerich, P., Veegar, C. S. \& Wood, H. C. S. (1965). Chemie 4, 6 ig.

McCormick, D. B., Arsensis, C. \& Hemmerich, P. (1963). F. biol. Chem. 238, 3095 .

McDougall, E. I. (1948). Biochem. F. 43, 99.

Miles, H. T. \& Stadtman, E. R. (1955). F. Am. chem. Soc. 77, 5746.

Owen, E. C. (1962). Proc. int. Congr. Fd Sci. I. London Vol. 3, p. 669.

Owen, E. C. \& West, D. W. (I968). Chemy Ind. p. 88 I.

Owen, E. C. \& West, D. W. (1970). Br. F. Nutr. 24, 45.

Tümmler, R., Steinfelder, K., Owen, E. C. \& West, D. W. (197r). Org. Mass Spec. 5, 4 I.

West, D. W. \& Owen, E. C. (1969). Br. F. Nutr. 233, 889 .

West, D. W., Owen, E. C. \& Taylor, M. M. (1967). Proc. Nutr. Soc. 26, xvii.

Wood, W. A. (r96r). In The Bacteria Vol. 2, p. 7 r [I. G. Gunsalus and R. V. Stanier, editors]. London:

Academic Press.

Wu, F. Y.-H., MacKenzie, R. E. \& McCormick, D. B. (I 970). Biochemistry, Easton 9, 2219.

Yanagita, T. \& Foster, J. W. (I956). F. biol. Chem. 221, 593. 